\title{
CARACTERIZACION DE LA EDUCACIÓN AL INTERIOR DE LOS CENTROS PENITENCIARIOS Y CARCELARIOS DE LA CIUDAD DE VALLEDUPAR
}

\section{CHARACTERIZATION OF EDUCATION INSIDE THE PENITENTIARY AND PRISON CENTERS OF THE CITY OF VALLEDUPAR}

\author{
Autor 1. \\ Flor Manuela Ariza Molina \\ Contador público, especialista en finanzas, magister en administración de \\ organizaciones. \\ Correo electrónico: flor.ariza@unad.edu.co \\ ORCID: https://orcid.org/0000-0001-8046-5040
}

\section{Autor 2.}

Fredys Padilla González

Contador público, especialista en educación superior a distancia, magister en mercadeo, candidato a magister en finanzas, doctor en gestión de la innovación. Correo electrónico: fredys.padilla@unad.edu.co

ORCID: https://orcid.org/0000-0002-9927-1585

Autor 3. Rafael Alberto Ovalle Castro Ingeniero industrial, especialista en gerencia de instituciones educativas, candidato a magister en ingeniería de administración.

Correo electrónico: rafael.ovalle@unad.edu.co

ORCID: https://orcid.org/my-orcid

\section{RESUMEN}

La educación según Núñez, V (1999) "es un derecho que hace a la condición del ser humano, ya que a partir de ella se construye el lazo de pertenencia a la sociedad, a la palabra, a la tradición, al lenguaje, en definitiva, a la transmisión y recreación de la cultura, esencial para la condición humana". Por lo anterior, toda persona que desee pertenecer a una sociedad y/o comunidad debe cumplir con el derecho a la educación, para recibir aceptación de sus semejantes. Esta investigación está orientada a consultar información en los Centros Penitenciarios y Carcelarios de Valledupar, respecto a la influencia que tiene la educación formal dentro del proceso de resocialización de los reclusos, observar sobre el comportamiento diferencial que pueden lograr perteneciendo o accediendo a la educación que le brinda el INPEC y las instituciones anexas al sistema.

Palabras clave: Reinserción, sistema penitenciario y carcelario, población carcelaria, tratamiento penitenciario, delitos.

\section{ABSTRACT}

Education according to Núñez, V. (1999) "is a right that makes the condition of the human being, since from it the bond of belonging to society, to the word, to tradition, to language, in short, to the transmission and recreation of Culture, 
essential for the human condition". Therefore, every person who wishes to belong to a society and / or community must fulfill the right to education, to receive acceptance from their peers. This research is oriented to consult information in the Penitentiary and Prison Centers of Valledupar, regarding the influence that formal education has in the process of resocialization of prisoners, observe about the differential behavior that they can achieve by belonging or accessing the education that they receive. provides the INPEC and the institutions attached to the system.

Keywords: Reintegration, penitentiary and prison system, prison population, prison treatment, crimes.

\section{INTRODUCCIÓN}

En esta investigación los datos serán tomados directamente de los Centros Penitenciarios y Carcelarios, los cuales son el Establecimiento Penitenciario de Alta y Mediana Seguridad y Carcelario de Valledupar - EPAMSCAVAL y el Establecimiento Penitenciario de Mediana Seguridad y Carcelario de Valledupar- EPMSCVAL.

De acuerdo con el modelo educativo para los Centros Penitenciarios y Carcelarios en Colombia, el INPEC (2009), menciona "Cuando iniciamos el proceso de construcción del Modelo, una primera inquietud se dirigió a indagar por la existencia de algunos de ellos en diversos países del mundo y en relación con formulaciones ideológicas diversas. Los escasos hallazgos nos pusieron frente a un panorama desolador: el problema no ha sido planteado sino en muy escasos lugares y en todos ellos se encuentra como referente casi universal el asumir que la educación en las prisiones debe reducirse a que el estado les permita a los presos terminar los estudios que no cursaron antes de ingresar a prisión con los métodos, contenidos y formas de evaluación y certificación iguales a aquellos que se usan para cualquier persona fuera de la prisión. Se trata esencialmente de ocupar el tiempo de los presos y permitirles acceder a información general que corresponde a conocimientos básicos sin utilidad práctica y sin demandas que trasciendan la simple repetición para recibir una certificación".

De igual forma indica "el problema de la educación en prisiones no es reducible al asunto de una mayor ilustración o el aumento en la erudición de quienes purgan sus condenas por las acciones que realizaron y que los condujeron a la situación de prisionalización. Es decir, la simple ilustración no conduce a la transformación del sujeto. No se construye una estética de la existencia distinta a aquella que produjo el acto delincuencial por el simple hecho de obtener el título de bachiller y de acceder a las informaciones generales que maneja un adolescente que termina, dentro de un colegio regular, sus estudios de educación básica y media" (INPEC, 2009).

El Modelo Educativo que ha implementado el INPEC (2019) está establecido sobre la base de los siguientes los principios:

- "El ser humano es un ser inconcluso, en permanente desarrollo humanístico e histórico."

- "La naturaleza humana se la dan las relaciones sociales históricas y los procesos de simbolización colectivos e institucionales que se generan sobre las mismas. Por lo tanto, el ser humano es de naturaleza biosicosocial, histórico y cultural."

- "El saber implica un saber pensar, o sea, saber producir saber, realizarlo y utilizarlo para su transformación y resignificación. Esto conlleva a un saber ser, es 
decir, quien soy, de donde vengo y para donde voy, como proyecto de vida"

"El proceso educativo se realiza a través del trabajo individual del interno, trabajo en grupo y un tercer momento de socialización de producciones. Se trabaja con el diseño de objetos de conocimiento que los internos desarrollan a través de preguntas e investigación". (INPEC, 2009) "El acompañamiento de los monitores se realiza en los patios, celdas y área educativa del establecimiento" (Lambuley, 2009, p.173).

Los Centros Carcelarios y Penitenciarios de la ciudad de Valledupar, siguen las directrices planteadas por el INPEC (2019), fundamentado en "Ios principios de la flexibilización, la autonomía, la coherencia, la integralidad, la dinamicidad, la democracia y la participación; donde desarrollan procesos educativos en sus diferentes formas, como la educación formal, informal y no formal, con el fin de contribuir en la resocialización de los internos".

"El modelo convoca a la generación de procesos educativos, cuyo propósito final es el de producir transformaciones en el sujeto y su condición existencial, respetando su dignidad, derechos y deberes". (Pontificia Universidad Bolivariana, 2006)

Según Pontificia Universidad Bolivariana (2006) "el modelo educativo implementado por el INPEC maneja tres aspectos en los que se focaliza la evaluación":

- "Evaluación del material educativo, compuesto por módulos, textos, talleres, videos, guías de trabajo, etc".

- "Las mediaciones pedagógicas, que comprende acompañamiento de los tutores, clases, talleres, seminarios, socializaciones, ambientes de aprendizaje, etc".

- "Producciones de los estudiantes, como escritos, socializaciones, informes orales, carteleras, videos, fotografías, entre otros (p.14)".

Con la expedición de las Resoluciones 7302 del 23 de noviembre de 2005 y la 2392 del 3 de mayo de 2006 por la cual se deroga la resolución 7447 de 2005, el Instituto Nacional Penitenciario y Carcelario INPEC, determina las pautas específicas por un lado en lo correspondiente a la atención integral y al tratamiento penitenciario que se le brinda a la población de internos.

De igual manera en el Artículo 10 se establecen las Fases del Tratamiento, sus objetivos, requisitos para la permanencia en cada una de ellas y programas que se ofrecen:

Para la fase de alta seguridad se ofrecen programas "orientados a la intervención individual y grupal a través de la educación formal, no formal e informal, en el desarrollo de habilidades y destrezas artísticas, artesanales, y de servicios; participación en grupos culturales, deportivos recreativos, literarios, espirituales y atención psicosocial."

Fase de mediana seguridad: "Los programas educativos y laborales que se ofrecen en esta fase se basan en la intervención individual y grupal; permiten el fortalecimiento de competencias psicosociales y ocupacionales a través de la educación formal, no formal e informal."

Fase de mínima seguridad: "accede el interno en programas educativos y laborales, en un espacio que implica medidas de restricción mínima y se orienta al fortalecimiento de su ámbito personal, de reestructuración de la dinámica familiar y laboral como estrategias para afrontar la integración social positiva y la consolidación de su proyecto de vida en libertad" 
La concepción de educación que fija la Ley 115 de 1994 en su artículo 10, el artículo 143 de la Ley 65 de 1993 dispone que: "El tratamiento penitenciario debe realizarse conforme a la dignidad humana y a las necesidades particulares de la personalidad de cada sujeto. Se verificará a través de la educación, la instrucción, el trabajo, la actividad cultural, recreativa, deportiva y las relaciones familiares".

El propósito de la investigación está encaminada al análisis de la educación en los Centros Penitenciarios y Carcelarios de la ciudad de Valledupar, teniendo en cuenta que ésta es un derecho adquirido por parte de los internos, de acuerdo con lo citado por Cosman (1976) "La educación es una función fundamental de las cárceles y, lo que es más importante, que el medio de la justicia penal es, en realidad un medio educativo que requiere una modificación a fondo de su paradigma".

\section{METODOLOGÍA}

El estudio fue descriptivo con diseño no experimental, la muestra fue de 128 internos; se aplicó una encuesta para identificar las características de la educación al interior de los Centros Penitenciarios y Carcelarios. Se utilizó para el análisis de datos el método estadístico Alpha de Cronbach. (Cronbach, J., 1951). Los criterios para definir el tamaño muestral se basaron en el cálculo de la muestra a partir de la siguiente fórmula:

\begin{tabular}{|c|c|c|c|}
\hline \multicolumn{4}{|c|}{$\begin{array}{l}\text { Para el cálculo del tamaño de } \\
\text { la muestra se usó: }\end{array}$} \\
\hline \multicolumn{4}{|c|}{$n=\frac{N \times Z_{a}{ }^{2} \times p \times q}{d^{2} \times(N-1)+Z_{a}^{2} \times p \times q}$} \\
\hline Tamaño de la muestra & 128,9314721 & RESULTADOS & \\
\hline Numerador & 653,45616 & RESULTADOS & \\
\hline Denominador & 5,068244 & RESULTADOS & \\
\hline $\mathrm{N}$ (Población) & 1890 & & \\
\hline$z$ & 1,96 & 3,8416 & \\
\hline$p$ & 0,9 & & Probabilidad de si ocurrencia \\
\hline$q$ & 0,1 & & Probabilidad de no ocurrencia. \\
\hline Margen de error & 0,05 & 0,0025 & \\
\hline
\end{tabular}

Fuente: elaboración propia

\section{DISCUSIÓN Y RESULTADOS}

La encuesta se aplica a los internos, donde la mayoría de los participantes se ubican en el rango de edad entre 18 a 30 años, para un total de 53 que representaba el $41.4 \%$, entre los 31 a 40 años con 71 internos (55.4\%) y entre los 51 años en adelante con 4 internos (3.1\%). (tabla 1).

Tabla 1.

Distribución por edad de los internos

\begin{tabular}{ccc}
\hline Edad & Número & Porcentaje \\
\hline 18 a 30 & 53 & 41.4 \\
31 a 50 & 71 & 55.4 \\
51 en adelante & 4 & 3.1 \\
Total & 128 & 100 \\
\hline & Fuente: elaboración propia \\
& &
\end{tabular}


Se identifica el nivel de escolaridad destacándose los internos con estudios de primaria con un $34.3 \%, n=44$, con estudios de secundaria $60.9 \%, n=78$ y los internos con estudios universitarios representaron el $4.7 \%, n=6$. (tabla 2).

Tabla 2.

Estructura familiar

\section{Clasificación Número Porcentaje}

\begin{tabular}{ccc}
\hline Primaria & 44 & 34.3 \\
Secundaria & 78 & 61 \\
Universitarios & 6 & 4.7 \\
Total & 128 & 100 \\
\hline
\end{tabular}

Fuente: elaboración propia

Se encuentra la distribución porcentual de programas que desean estudiar los internos, predominando con mayor aceptación el programa de Administración de Empresas con un $25.8 \%$, continúa el programa de psicología con un $24.2 \%$ y en tercer puesto el programa de derecho con un $21.9 \%$. Lo que indica la necesidad de socialización que tienen los internos por lo que anhelan conocer acerca de sus derechos y normas legales, así mismo conocer la parte psicológica para poder tener un mejor vivir dentro y fuera del Centro y en lo referente a la Administración de Empresas, los internos sueñan tener su propia empresa cuando culminen su condena y poder emplear a otros. (tabla 3 ).

Tabla 3.

Distribución porcentual de programas que desean estudiar los internos

\begin{tabular}{ccc}
$\begin{array}{c}\text { Programas } \\
\text { Derecho }\end{array}$ & $\begin{array}{c}\text { Núm } \\
\text { ero }\end{array}$ & $\begin{array}{c}\text { Porcent } \\
\text { aje }\end{array}$ \\
$\begin{array}{c}\text { Administración de } \\
\text { Empresas }\end{array}$ & 28 & 21.9 \\
Contaduría Pública & 6 & 25.8 \\
Ingeniería de Sistemas & 3 & 4.7 \\
Psicología & 31 & 2.3 \\
Comunicación Social & 3 & 2.3 \\
Ingeniería Industrial & 4 & 3.1 \\
Veterinaria & 4 & 3.1 \\
Ingeniería Ambiental & 9 & 7 \\
Economía & 3 & 2.3 \\
Licenciatura en & 4 & 3.1 \\
Matemáticas & 128 & 100 \\
Total & \multicolumn{2}{c}{ Fuente: elaboración propia }
\end{tabular}

Fuente: elaboración propia 
Los resultados encontrados en esta investigación evidencian un porcentaje significativo de internos que falta por explotar y aprovechar por parte de la UNAD, con la oferta de programas, teniendo en cuenta el nivel de escolaridad y edad que tienen los internos. La educación en los Centros Penitenciarios y Carcelarios es pertinente si responde con las peticiones sociales como a las necesidades propias de los internos que serán sus actores dentro de la sociedad, en donde dé lugar a otros modos de pensar, de actuar, de comprender y de convivencia dentro de la sociedad actual. Para ello es importante que exista transferencia de conocimiento entre el tutor y el estudiante, con el fin de recuperar todos los conocimientos que ellos tienen, para tener una vida útil dentro del centro penitenciario y fuera de él, lo que ayudaría en su vida personal para ser aceptado en una sociedad.

Es importante resaltar que hoy día la UNAD tiene unos estudiantes internos en los Centros carcelarios, los cuales se deben motivar para que continúen con sus estudios y evitar la deserción; como lo expresan Cervantes, M. \& Narváez, M. (2018) "mediante el acuerdo 002 del 30 de enero de 2018 se estableció la Política Nacional de Retención y Permanencia estudiantil que pretende incrementar significativamente la retención y la permanencia estudiantil mediante el trabajo colaborativo de todos los actores y académicos en pro de la mejora continua en la gestión académica, pedagógica, administrativa y financiera que permita la satisfacción y motivación de los estudiantes de primera matricula (UNAD, 2018) "

\section{CONCLUSIONES}

Según el Mayor General Morales (2007), "la educación se constituye en un bien y un derecho que es inalienable en cuanto su negación se constituiría en un desconocimiento a la dignidad como una construcción a la que estamos obligados por estar llamados a la plenitud de la condición humana."

El Estado colombiano y los diferentes entes educativos, le brindan a los internos de los diferentes Centros Penitenciarios y carcelarios, las herramientas, beneficios, espacios e intercambio de conocimientos con el fin de ayudarlos no solo a prepararse académicamente, sino que en su parte psicosocial ellos puedan resocializarse al servicio de la sociedad y un mejor vivir para ellos, su familia y todo su entorno; creándose así momentos emocionales, de alegría y de paz bajo una sana convivencia, pacífica y armónica.

EI INPEC, busca a través de diferentes estrategias que el interno se capacite en las diferentes oportunidades de actividades educativas, culturales y laborales, para que se prepare laboral y socialmente y se reintegre con éxito a la sociedad.

\section{REFERENCIAS}

Cervantes, M. y Narváez, M. (2018). Estudio prospectivo y estratégico para la gestión de la retención y la permanencia en el programa administración de empresas de la universidad nacional abierta y a distancia - UNAD. (s.d.).

Congreso de la República de Colombia. (1994). Ley 115, por la cual se expide la ley general de la educación. Recuperado de https://www.mineducacion.gov.co/1621/articles-85906_archivo_pdf.pdf 
Congreso de la Republica de Colombia. (1993). Ley 65, articulo 21. Por la cual se expide el Código Penitenciario y Carcelario. Recuperado de

http://wp.presidencia.gov.co/sitios/normativa/leyes/Documents/Juridica/Ley \%2065\%20de\%201993.pdf

Cronbach, J., (1951). Coeficiente Alpha de Cronbach. (s.f.)

Instituto Nacional Penitenciario y Carcelario. (2019). Regional Norte. Recuperado de http://www.inpec.gov.co/institucion/organizacion/establecimientospenitenciarios/regional-norte

Instituto Nacional Penitenciario y Carcelario. (2009). Modelo Educativo para el Sistema Penitenciario y Carcelario Colombiano.

Instituto Nacional Penitenciario y Carcelario INPEC. (2005). Resolución 7302 grupo de prisiones. Recuperado de https://grupodeprisiones.uniandes.edu.co/images/RESOLUCI\%C3\%93N_7302 _DE_2005_.pdf

Lambuley, H. (2009). Colombia apuesta a un modelo educativo para la inclusión social de adultos en prisión. Recuperado de http://www.proeda.cl/biblioeda/educacion-encarceles/5-colombia-apuestaun-modelo-educativo-para-la-inclusion-social.pdf

Morales, E. (2007). Discurso pronunciado en acto oficial de presentación a la sociedad colombiana del Modelo Educativo.

Núñez, V. (1999). Pedagogía Social: cartas para navegar en el nuevo milenio. Buenos Aires, Argentina: Edit. Santillana.

Pontificia Universidad Bolivariana. (2006). Modelo Educativo. Componente Administrativo. Recuperado de http://www.inpec.gov.co/portal/page/portal /INPEC_CONTENIDO/Derechos\%20Humanos/MODELO\%20EDUCATIVO 